\title{
LÓGICAS DE VINCULAÇÃo NA ARTE
}

\author{
Sílvia Pinto \& Moisés de Lemos Martins
}

\begin{abstract}
Resumo
A obra de arte produzida nos seus primórdios só muito mais tarde foi reconhecida como tal. Na mesma ordem de ideias, a função artística da obra de arte atual, no futuro, poderá tornar-se novamente acidental. Com efeito, em época alguma, a arte respondeu a exigências unicamente estéticas. Partindo destes pressupostos de Walter Benjamin (1936-1939/1992), tentaremos aplicar à arte os conceitos de "vinculação" (com origem na etologia) e de "redes de vinculação" (utilizado em neurociência), para explicar aspetos característicos da metafísica da imagem, comuns à arte e à religião.Seguindo uma perspetiva histórica, tentaremos mostrar a evolução da arte segundo três principais lógicas de vinculação: a arte como atividade mágica (também na sua relação com a lógica do índice); a arte como mimesis; e a arte como linguagem. A imagem, ou melhor, as múltiplas realidades que designamos por "imagem", assume cada um destes vínculos, alternada ou simultaneamente, pois deles é sua herdeira. Tendo em conta o atual contexto de hipervisibilidade de imagens mediáticas, esperamos, com este estudo, mostrar a importância da arte e da sua ascendência mítico-religiosa na redefinição da imagem mediática.
\end{abstract}

\section{Palavras-chave}

Artes visuais; estética; imagem; imagem mediática; magia-mimesis-linguagem

\begin{abstract}
The work of art produced in its origins was only much later recognized as such. Similarly, the artistic function of current art objects in the future may become accidental again. In fact, at no time has art ever answered exclusively to aesthetic demands. From these assumptions by Walter Benjamin (1936-1939/1992), we will attempt to apply to art the concepts of "binding" (original of ethology) and of "linking networks" (used in neuroscience) to explain distinctive aspects of image metaphysics, shared by art and religion. From a historical perspective, we will attempt to show the evolution of art in three main binding logics: art as a magical activity (also in relation to index logic); art as mimesis; and art as language. The image, or rather the multiple realities we call "image", takes each one of these links, in an exchanging or simultaneous way, since image is their heiress. Taking into account the present context of media images hypervisibility, we aim, with this study, to show the importance of art and its mythical-religious ascendance in what concerns media image redefinition.
\end{abstract}

\section{Keywords}

Aesthetics, image-picture, magic-mimesis-language, media image, visual arts

\section{INTRODUÇÃo}

A obra de arte produzida nos seus primórdios só muito mais tarde foi reconhecida como tal. Da mesma forma, a obra de arte atual adquiriu a função artística, o que 
no futuro poderá tornar-se novamente acidental. Esta ideia de Walter Benjamin (19361939/1992, pp. 86-87) pressupõe uma outra - a de que as mudanças ao nível da função social da arte, vistas muitas vezes como sintomas de uma crise na comunicação entre a arte e o público, contêm os sinais de uma rutura e renovação ao nível de um conjunto de ligações com o outro, a vida, a morte, a história ou o tempo, a que chamaremos "lógicas de vinculação".

O termo vinculação [de vínculo: aquilo que liga ou, figurativamente, estabelece uma relação], original da etologia e desenvolvido pelo psicólogo John Boulby nos anos 50, refere-se à nossa necessidade de estabelecermos laços afetivos específicos. Daniel Goleman (2006) utiliza a expressão redes de vinculação para falar das grandes redes neurais das nossas principais forças afetivas. Estes circuitos neurais não apenas interagem em diversas combinações no amor, na amizade, na compaixão, ou no afeto pelos animais, como operam, em maior ou menor grau, em domínios como o anseio espiritual ou a paixão pelos espaços abertos ou as praias desertas. As redes de vinculação estabelecem-se sempre que se estabelece qualquer tipo de relação neural com alguém ou alguma coisa. O cérebro responde à ilusão criada pelas imagens com os mesmos circuitos neurais com que responde à vida real. As imagens invadem o nosso cérebro, tal como a vida em geral, a partir da mais pequena interação.

Como aprendemos com Malraux (1965/2000, p. 11), um crucifixo não era, inicialmente, uma escultura, assim como uma Madonna não era um quadro (isto é, objetos de arte). A fotografia não parece ter sido, deste ponto de vista, uma exceção. Como defende Debray (1994, p. 33), a imagem assumiu sempre uma função mediadora entre os vivos e os mortos, o homem e os deuses, as comunidades e as cosmologias, o visível e o invisível. Benjamin conhecia bem as diferentes exigências impostas à arte:

em época alguma a arte respondeu a exigências unicamente estéticas. Os escultores góticos serviam a Deus fazendo estátuas para seus fiéis; os retratistas visavam à semelhança; os pêssegos e as lebres de um Chardin tinham seu lugar na sala de jantar, acima da mesa de refeição familiar. Os artistas, em alguns casos, aliás muito raros, sofriam com isso; a arte, em seu conjunto, se beneficiava; foi assim em todas as grandes épocas artísticas. Em particular, a ingénua convicção de que apenas 'copiavam a natureza' era tão salutar para os pintores dessas épocas felizes quanto teoricamente injustificável. (Benjamin, 1982/2009, p. 728)

Seguindo uma perspetiva histórica, tentaremos mostrar a evolução das diferentes vocações artísticas - da atividade mágico-religiosa à arte (como hoje a conhecemos) a partir das lógicas de vinculação na arte, que consideramos mais relevantes ao longo dos tempos: [1] a arte como atividade mágica; [2] a arte como mimesis; [3] a arte como linguagem; [4] a arte sob a lógica do índice. A imagem, ou melhor, as múltiplas realidades que designamos por "imagem", assume cada um destes vínculos, alternada ou em simultaneamente, ou, pelo menos, deles é sua herdeira.

Como bem observou Giulio Carlo Argan (1984, p. 15), em 1984, no nosso tempo, mais do que em qualquer outra época, o mundo ocupa-se de arte, e nunca, como hoje, 
a pintura gozou de tão elevado prestígio. Durante os anos 70, cada cidade queria ter o seu museu, como no dealbar do século XI, cada cidade queria ter a sua catedral. Tem razão Jean Clair (1992, pp. 9-14) ao salientar que, hoje, é o culto da arte que regula as transumâncias culturais do turismo ocidental. Poucas são as obras que resistiram aos laços seculares com a sua terra e os seus motivos e permanecem no seu lugar original de exposição e culto. Circular tornou-se, no século XX, um valor em si, independente de qualquer juízo expresso sobre os objetos introduzidos no circuito. Jean Clair individua uma relação direta entre a proliferação dos meios de divulgação e dos museus de Arte Moderna e a sua crise, como se a compulsão para a conservação das suas obras fosse a tentativa de mascarar o pressentimento de um fim.

Entretanto Malraux (1965/200o, pp. 11-12) chama a atenção para o facto de os museus terem imposto ao espectador uma relação totalmente nova com a obra. Até ao século XIX, só aos olhos do pintor a pintura era pintura. Para todos os outros, a pintura era sempre algo mais. O museu suprime os retratos, ao mesmo tempo que extirpa a função às obras de arte. Não reconhece santos nem Cristo; objetos de veneração, semeIhança, imaginação ou posse, mas apenas imagens de coisas, diferentes das próprias coisas. Desta diferença específica, retira a sua razão de ser. O museu ressuscitou um conjunto de artes, ao mesmo tempo que matou outras, cujo domínio permanece vasto e complexo. Quando Benjamin escreve que na era da reprodutibilidade da obra de arte "é a aura que murcha", refere-se a este deslocamento do lugar de culto das obras, da sua terra natal, para o lugar da ocorrência de massa. Um tal lugar estendeu-se, atualmente, dos livros à circulação online do cibermuseu.

Este percurso permitir-nos-á compreender não só o deslocamento histórico da passagem pós-moderna de uma estética da analogia a uma estética do contacto, mas também repensar o nosso lugar entre as diferentes fases históricas da criação - o nosso desejo de exercer poder ('mágico') sobre a existência; a nossa necessidade de imitar e fazer amar aquilo que imitamos; a nossa necessidade de fazer ver e sermos vistos - a necessidade de vínculos. Esta perspetiva crítica possibilitar-nos-á, ainda, compreender o que têm em comum a fotografia como prática social e a prática artística, e religar ambas à tradição das imagens sagradas, das imagens-verdade, à magia, à loucura, ao amor e à morte, que sempre foram motores fundadores da criação artística.

\section{A ARTE COMO ATIVIDADE MÁGICA}

Diferentes investigadores da pré-história parecem estar de acordo quanto à função ou motivação primeira que estaria por trás da produção das primeiras imagens-objetos que se conhecem. O pintor da era paleolítica é, simultaneamente, o pintor e o caçador que acredita encontrar-se na posse do próprio objeto, a partir do momento em que possui a sua imagem. A sua representação não é um belo objeto de contemplação, mas um projeto de ação que vale como antecipação do efeito desejado - um poderoso instrumento ao serviço da subsistência, da fertilidade e da necessidade de assegurar uma descendência. A representação e a coisa representada são ainda uma e a mesma coisa, 
assim como o desejo e a sua realização. A única diferenciação entre a imagem e a realidade parece estar no tempo que as separa (Gombrich, 1986; Hauser, 1951).

Para Debray (1994, pp. 13-43), a arte chega à imagem quando a magia se retira. Efetivamente, a noção que criamos de arte - que é grega - é concebida na mimesis. Mas se a arte do início dos tempos possa ter sido "mágica" apenas involuntariamente, os aspetos que dela persistem não brotaram unicamente do "encontro entre o pânico e a técnica", como defende o autor francês. As imagens, quer provoquem alívio, terror, ou deleite, contêm sempre a potência de um efeito. O que muda, em função dos lugares e dos tempos, é a sua capacidade - e a daqueles a quem são dirigidas - de dar resposta ao seu apelo. A inscrição, que se pode ler numa estátua funerária ou votiva, é sempre o resultado de um laço ou de um voto - um pacto - que através dela se estabelece.

Ao contrário da mimesis, conceção que dominará a arte ocidental desde a antiguidade até ao modernismo, a representação não é aqui uma projeção canonizada do passado, mas uma imagem de visualização de um futuro promitente. Sob este ponto de vista, esta prática não parece longe dos difíceis exercícios de imaginação nos quais somos hoje introduzidos no âmbito dos mais atuais estudos e práticas do pensamento positivo. Apesar disso, a nós, herdeiros da diferenciação entre realidade e aparência, poderá parecer-nos que a nossa condição contemporânea em tudo se distancia desta primeira, e que o pensamento mágico em nada nos caracteriza. Porém, tanto a manipulação e a tortura, como a publicidade e o cinema, tiram partido deste conhecimento: que o racionalismo da imagem pouco efeito tem sobre os homens quando se encontram perante aquilo a que António Damásio (2003) designou de "objetos emocionalmente competentes" - estímulos suficientemente capazes de desencadear mapas de circuitos neurais pré-existentes.

Tendo em conta a tradição da imagem como imagem do homem (que se opõe à tese da abstração como imagem primeira), podemos dizer que a função primordial da imagem-arte-religiosa é tornar presente alguém ausente, através da figuração da sua imagem. A origem latina da palavra imagem (imago) designa isso mesmo - efígie, estátua (funerária ou não). Segundo a narrativa de Plínio, o Velho (c. 1470-1561, vol. XXXV, pp. 1084-1120), a pintura nasceu quando foi possível circunscrever, pela primeira vez, com uma linha, a sombra de um ser humano. Esta imagem-sombra dos primórdios mostra-nos o nascimento da representação artística ocidental como um nascimento em negativo, sob o signo de uma ausência-presença - a ausência do corpo e a presença da sua projeção.

A narrativa de Plínio, o Velho, tem como principal objetivo descrever o gesto fundador da cerâmica e do desenho, que a tradição fez com que fosse alargado à pintura e à escultura por modelagem. Mas o mito leva-nos mais longe quando nos insere num quarto iluminado, onde os dois amantes se amam e se despedem, a sua sombra é projetada na parede, e a rapariga, num gesto antecipador da saudade que sentiria na ausência do seu amante, fixa o contorno da silhueta do objeto do seu amor. É Plínio quem nos diz que a pintura nasceu desde que se começou a delimitar o contorno da sombra humana. A fábula da filha do ceramista diz-nos, ainda, que a pintura nasceu desde que o Homem amou e conheceu o medo da sua perda. 
Como explica Victor Stoichita (2008), na tese que seguimos como referência, a realidade histórica dos primórdios da imagem coloca-nos, assim, perante um facto inequívoco da metafísica da imagem, cuja origem pode procurar-se na relação erótica interrompida, na separação, no ser que parte, donde resulta o caráter substitutivo da imagem. A primeira função da imagem é, graças à sua semelhança com o modelo ausente, a de suporte mnemónico: tornar presente o que é ausente. A segunda função deriva do facto de a sombra pertencer a alguém que esteve envolvido numa relação de contacto. $A$ imagem-sombra tem a função de gravar uma marca de alguém ausente, imortalizando a sua presença sob a forma de uma imagem fixada no tempo, adquirindo, assim, um valor propiciatório'.

A história que Plínio (século XV) evoca, recorrendo a uma fábula com origens no Egipto, veicula, assim, um conjunto de aspetos comuns à cultura grega e à cultura egípcia. Como aprofunda Victor Stoichiza (2008), na sua Breve História da Sombra, tanto a Grécia como o Egipto antigos estabeleciam uma ligação simbólica entre a sombra, a alma e a ideia de duplo dos seres humanos. No Egipto, existiam duas sombras que se manifestavam em momentos distintos: enquanto o homem vivia, a sombra exteriorizava-se na sombra negra (khaibit); no instante da morte, no momento em que a sombra negra desaparecia, o $K a$ (a sombra clara de um colorido aéreo) assumia a função de duplo, graças à incorporação mágica da alma no Ka da estátua-múmia. A estátua-múmia tornava-se, assim, a incorporação da eidolon (uma imagem sem substância) no colossos (o duplo animado), na prática, o substituto "vivo" do corpo morto, vivificado na alma-sombra do Ka.

Tanto os egiptólogos como os helenistas defendem que a estátua nasce por uma de duas razões: ou para ocupar o lugar de um deus, ou para ocupar o lugar de um morto. Como confirma Bazin (1945/1981, p. 9), nas origens da pintura e da escultura encontra-se o complexo da múmia. A religião egípcia, dirigida toda ela contra a morte, fazia depender a sobrevivência dos seres da perenidade material dos corpos, satisfazendo, desse modo, uma necessidade fundamental da psicologia humana: a defesa contra o tempo. Era natural salvar a vida da morte na carne e nos ossos. Assim, a primeira estátua egípcia é a múmia do homem curtido e petrificado no natrão. Mas a preservação do corpo não era suficiente. Era necessário que a sua fiel imagem fosse também preservada, uma vez que a função primordial da estátua egípcia era salvar o ser pela aparência.

Provavelmente, graças a essa motivação - a de salvar o ser pela aparência - o retrato é o género que, por excelência, parece ter sido consagrado à semelhança, como a um serviço - um serviço de verdade em que se presta uma homenagem, que não está longe do serviço religioso (Nancy, 2006, p. 38). Assim, enquanto substituto de uma pessoa, a estátua era necessariamente vista como animada. Por essa razão, como refere Levin

\footnotetext{
"No Velho Testamento, o propiciatório era o símbolo do "trono" de Deus, isto é, simboliza a presença de Deus. No Dia da Expiação, o sumo-sacerdote aspergia o sangue dos animais sacrificados sobre e diante do propiciatório, para a remissão dos pecados do povo de Israel (Levítico 16, 14-15). Parece implícito, neste caráter propiciatório das estátuas-múmias, o mesmo tipo de valor que é atribuído às relíquias cristãs (Do lat. reliquia, plural neutro de reliquium, "coisa deixada"). Quer se refira a um deus ou de um santo, em ambos os casos, a relíquia é algo precioso ou raro, como um objeto que lhe tenha pertencido, ou o seu próprio corpo, nem que seja apenas uma parte dele, que as pessoas veneram.
} 
(1971, p. 27), os egípcios canalizavam a luz do sol através de pequenas fendas abertas no telhado das pirâmides, estudadas para dirigir a luz, em forma de holofote, em direção às estátuas que se encontravam no seu interior, para, literalmente, "animar" as estátuas com a luz do sol, segundo o movimento natural do astro.

Segundo Ernst Gombrich (1985, pp. 106-110), o escultor egípcio era designado como "aquele que mantém vivo", por eternizar a vida dos mortos. Assim como a "Grande Esfinge" foi concebida tal uma sentinela vigilante, para sempre, da mesma forma, o retrato do dono de um túmulo dado à visão dos camponeses da sua propriedade, não é o simples registo da sua vida passada, mas uma presença que tem o poder de vigiar o trabalho dos seus empregados, através do ciclo interminável dos anos. As cenas da vida diária têm que ser lidas, mas a sua sequência é puramente conceptual, e não narrativa. As imagens representam, simultaneamente, o que foi, o que é e o que há-de ser, como um eterno presente. Fazer e registar estão aqui fundidos na mesma promessa de deter em lúcidas imagens o caráter evanescente do tempo.

\section{A ARTE COMO MIMESIS}

Como observa Benjamin (1936-1939/1992, p. 75), a obra de arte sempre foi reproduzível. Os homens sempre puderam imitar o que haviam feito antes. Porém, a descoberta da diferenciação entre original e cópia, poderá ter sido um mero "efeito em cadeia" (Hanfmann citado em Gombrich, 1989), no início do processo de produção de imagens. Com os Gregos, o aparecimento da indústria da reprodução para venda (a fundição e a cunhagem $)^{2}$ retirou a imagem e o objeto do contexto para o qual tinham sido concebidos, introduzindo-os nas casas particulares - tratou-se de atribuir à arte uma nova função, dado que esta situação da arte era até então inexistente. Por este motivo, podemos dizer que os gregos inventaram a arte.

A teoria da mimese, que Platão desenvolve entre A República (século IV a.c./2010) e O Sofista (século IV a.c./2012), marca o triunfo do espelho sobre a sombra. A imagem-sombra (phantasmata), dado o estatuto ambíguo que lhe é atribuído, passa a desempenhar um papel secundário na arte de copiar, cedendo o lugar de maior importância à imagem-espelho (eidola) que, submetendo-se às leis da mimesis, passará a ser-lhe superior. É em virtude do platonismo que a obra de arte se dobrará às exigências do paradigma especular e a projeção da sombra se limitará a um papel marginal, o que não significa que venha a ser eliminada do arsenal da representação. Porém, passará a ser a parente pobre de qualquer reflexo, e o seu estatuto permanecerá vago e marcado por poderes obscuros ${ }^{3}$.

No curso da história da representação ocidental, foi Platão quem desferiu o primeiro golpe na "sombra". Mas será a primeira teoria da arte, em pleno Renascimento, a

\footnotetext{
${ }^{2}$ Aprofundamento das primeiras técnicas de reprodução em Benjamin (1936-1939/1992, pp. 75-76) e Sicard (2006, pp. 23-104).

3 Para aprofundamento da "vitória do espelho sobre a sombra", consultar Victor Stoichita (2008). Breve storia dell'ombra. Milano: Il Saggiatore (pp. 29-39).
} 
reivindicar explicitamente para si o paradigma especular. No texto fundador da pintura dos tempos modernos, De Pictura, Leon Battista Alberti (1435) apresenta a teoria da nova arte, sob o signo de Narciso. Esta nova ideia de imagem pictórica assume-se como consequência de um ato erótico, tal como no mito pliniano, porém, invertendo os papéis: aqui, a pintura concerne o eu, e não o outro.

Pouco mais de um século depois, Giorgio Vasari (1568), numa sobreposição discutível das duas versões do mito fundador - a de Plínio e a de Alberti - criará uma terceira versão do mesmo. Referindo-se ao texto de Plínio, Vasari transforma o retrato, de sombra do outro num autorretrato de sombra, reafirmando a relação dos primórdios da arte com o paradigma especular, que se depreende do mito de Narciso.

À parte a impossibilidade figurativa e o paradoxo teórico, que Philippe Dubois (1992, pp. 118-123) demonstra no Acto Fotográfico ${ }^{4}$, somente com a aparição do dispositivo fotográfico será possível assegurar a representação direta do representado. Não obstante as contradições do dispositivo especular, Stoichita (2008, p. 39) confirma aquilo que Vasari procurou deixar claro, que a arte sobre a qual pretendia fazer história era aquela que encorporou o "estado da sombra no estado do espelho", cujo arquétipo seria o mito de Narciso, eleito por Alberti. Efetivamente, a arte que fez história até ao advento da Arte Moderna foi aquela que Platão declarou como superior e única arte aceitável - a "arte da cópia", regida pelas leis da representação mimética.

Curiosamente, segundo dados da Neurociência (Goleman, 2006), o cérebro responde à ilusão criada pelas imagens com os mesmos circuitos com que responde à vida real. Com efeito, estudos desenvolvidos sobre o contágio ecrã-espectador mostram como os "filmes que vemos", literal e metaforicamente, dominam o nosso cérebro. Por outro lado, investigadores suecos descobriram que sempre que olhamos para uma foto de alguém cujo rosto revela uma emoção forte, os nossos músculos faciais começam automaticamente a imitar a expressão que vemos, desencadeando em nós os sentimentos correspondentes. Este fenómeno, denominado "imitação reflexa", é mais uma ponte cérebro-a-cérebro pela qual nos expomos, involuntariamente, a influências emocionais, reproduzindo circuitos neurais preexistentes, mais ou menos desejáveis.

As emoções são contagiosas tanto na vida como na arte, porque "uma coisa é real se é real nas suas consequências" (Goleman, 2006, p. 37). Assim, o cérebro responde a situações de empatia, reais ou representadas, "acendendo" determinados circuitos neurais preexistentes. Quando duas pessoas sentem uma relação, as suas fisiologias sintonizam-se: os olhos encontram-se, os corpos aproximam-se, e nos relacionamentos mais fortes, as posturas e os movimentos entre as pessoas, copiam-se. Aristóteles identificou o prazer da imitação no processo de aprendizagem. Os circuitos desta ressonância parecem estar incorporados no próprio sistema nervoso humano, uma vez que ainda no útero, o bebé já sincroniza os seus movimentos com os ritmos da fala humana. Pelo

\footnotetext{
${ }_{4}^{4}$ Sobre a impossibilidade figurativa do autorretrato de sombra, Dubois (1992, p. 119) escreve o seguinte: "A mão que desenha, em particular, não poderá nunca desenhar-se desenhando: para isso deveria parar, para imobilizar a sua sombra, mas imediatamente interromperia o próprio acto de desenhar. Ou então, ela bem pode correr atrás de si própria, e o mais depressa que possa, que nunca se há-se apanhar".
} 
contrário, quando a relação não se estabelece, a voz e os corpos desenham o retrato de uma desconexão - a impossibilidade de estabelecer laços.

\section{A ARTE COMO LINGUAGEM}

Para Rosalind Kraus (2002, pp. 63-75), a ambição naturalista com que os impressionistas saíram dos seus ateliers para conquistar o mundo, foi-se convertendo, progressivamente, numa introversão e imprecisão crescentes, numa perda de inteligibilidade. $O$ estilo impressionista foi-se tornando num obstáculo à criação de vínculos entre o pintor e o seu sujeito. A ilusão pictórica fragmentou-se em depósitos de pigmentos, camadas de tinta e manchas brancas de tela por pintar. As telas impressionistas são apontamentos inacabados de luz e cor, em forma de manchas justapostas - aquilo que no passado se denominava "esboços".

Até à data, para que um quadro fosse considerado como tal, era necessária uma visão unificadora que estruturasse e estabelecesse vínculos entre os elementos. Os impressionistas, transformando a unidade visível da sua própria introspeção numa organização sistémica da perceção, criaram uma nova função para a arte - a arte como linguagem ou sistema de signos - para muitos, o primeiro capítulo da Arte Moderna.

Segunda a definição de Filiberto Menna (1983, p. XI), a Arte Moderna nasce da aquisição teórica e operativa da natureza convencional e abstrata da linguagem artística. Essa aquisição opera uma verdadeira rutura epistemológica na problemática da arte, em relação a uma conceção naturalista da linguagem, problematizando o pressuposto de uma correspondência imediata entre linguagem e realidade. Segundo esta conceção, a arte que não se apercebeu desta passagem sem retorno, não é Arte Moderna, mas somente cronologicamente contemporânea.

Filiberto Menna (1983) mostra ainda como a "linha analítica da Arte Moderna" contribui para colocar em crise, no campo da arte, uma episteme fundada na continuidade e na semelhança, para abrir deste modo a via a uma episteme fundada na descontinuidade e na diferença. No Simbolismo, a arte é ainda ciência da analogia, enfim, uma hermenêutica enquanto técnica de decifração dos signos da natureza. Com o Impressionismo, e em particular com Cézanne e Seurat, a pintura torna-se semiologia (Menna, 1983, p. 96). A Arte Conceptual e as pontas mais extremisticamente analíticas da Art-Language marcam o auge da refundação da linguagem da Arte Moderna, levando até às últimas consequências o processo de abstração da linguagem artística. É suposto que uma linguagem comunique, que sirva para partilhar, ou para tornar comum a outros, a nossa experiência do mundo. Porém, a arte começa a tornar-se linguagem no momento da fundação da Estética enquanto disciplina, ao reclamar o seu direito à autonomia em relação a qualquer função social, funcional, hedonística ou moral.

Walter Benjamin (1936-1939/1992, p. 83) justifica a emergência da "arte pela arte" como uma reação à crise oitocentista, que se manifestou numa "teologia da arte [pura]". Aqui, a prática artística deixa de ser mimesis - uma experiência deduzida da natureza enquanto princípio metafísico de revelação - para se tornar poiesis - sem qualquer fim 
para além do seu próprio fazer. A palavra "autonomia" traduz a condição do que é para si próprio, e apenas para si próprio, como refere Steiner (1993, p. 58). Com a emergência da Arte Moderna e a rutura do pacto mimético que regia o reconhecimento do mundo, até ao fim da idade clássica, a arte que afirma a sua autonomia, reduz-se à sua própria linguagem.

Até ao final do século XVI, porém, a linguagem não é um ser arbitrário, que prolifera indistintamente, nem um mero episódio na história da língua 5 . A linguagem foi dada ao mundo por Deus e marcada ("assinada") ${ }^{6}$ pela sua imagem e sombra, tal como todas as coisas da natureza. Não há diferença entre as marcas visíveis que Deus colocou sobre a Terra e as palavras legíveis da Sagrada Escritura ou de outros textos antigos, que a tradição escolheu. A relação com os textos é da mesma natureza que a relação com as coisas - ambos se propõem aos homens como enigmas a decifrar. E é de marcas ("signatures") que os homens se servem, num e noutro caso, para conhecer. A experiência da linguagem pertence à mesma rede arqueológica a que pertence a representação e o conhecimento das coisas da natureza. Conhecer é apropriar-se do sistema das semeIhanças, tornando-as próximas e solidárias umas das outras.

Segundo George Steiner (1998, pp. 87-89), a rutura do pacto com a linguagem, que reflete a nossa relação com Deus, constitui uma das mais profundas revoluções do espírito na história do Ocidente e define a própria Modernidade. Aqui é desfeito o ato de confiança semântico, que ocorre na linguagem quando esta é capaz de estabelecer vínculos entre os seres, e entre estes e os objetos a que se referem. A aliança entre as palavras, as imagens e as coisas pressupunha que o ser é suficientemente "dizível".

Não obstante a redução da arte à semiótica, como decorre das pesquisas mais analíticas da Arte Moderna, a semelhança e as suas figuras não cessam, todavia, de agir improvisadamente dentro da nova episteme, encontrando no campo da arte um terreno rico de possibilidades para novas situações de equilíbrio com as novas tendências analíticas.

Parafraseando dois grandes autores, "a arte é um modo especial de pensar" (Rosenberg, 1972) no qual se inventam novos "modos de fazer mundos" (Goodman, 1978); não pode, pois, renunciar à sua função hermenêutica, segundo o projeto mais rigorosamente analítico, nem à sua exigência irrenunciável de nomeação - essa é a sua condição primeira, enquanto linguagem. E este é o abismo desse encontro: a denominação poética e a denominação comunicativa (Menna, 1983, p. 99).

\section{A ARTE SOB A LÓGICA Do ÍNDICE}

Walter Benjamin (1936-1939/1992, pp. 77-83) antevê no princípio de reprodução técnica uma mudança sem precedentes na história da cultura - a perda da aura ou do seu "aqui e agora" - a existência única do encontro, que constitui o remanescente

\footnotetext{
${ }_{5}$ Para todas as considerações feitas sobre a linguagem até aos séculos XVI e XVII, ver Foucault, M. (1966/1998). A prosa do mundo. In M. Foucault, As Palauras e as Coisas. Uma Arqueologia das Ciências Humanas (pp.73-99). Lisboa: Edições 70.

${ }^{6} \mathrm{Na}$ obra de Foucault (1966/1998, p. 81) que referimos, o capítulo dedicado às "marcas" é intitulado "signatures".
} 
da função ritual, ainda que se trate de um ritual secularizado. Quer apropriando-se da totalidade das obras de arte, quer conquistando o seu lugar entre os procedimentos artísticos, o que se subtrai à reprodutibilidade técnica é o princípio de autenticidade, que com a secularização da arte, toma o lugar do valor de culto das suas obras. A perda da aura, do seu "aqui e agora", anula o testemunho singular desse encontro, irreproduzível.

$\mathrm{Na}$ época contemporânea, as fotografias transformaram-se na experiência visual, por excelência. Grande parte das obras da Arte Povera, da Land Art ou da Body Art são produzidas para serem fotografadas, uma vez que, quer pelas dimensões das obras in locus, quer pela sua efemeridade, muitas vezes não é possível conhecer a obra, a não ser através do seu registo fotográfico. A fotografia começou por invadir, assim, os espaços de exposição da arte e o campo da crítica, no momento de afirmação da própria modernidade, assinalando o ressurgimento de uma nova forma de aura. Hoje, como diria Susan Sontag (1986, p. 133), toda a arte "aspira às características de objeto reprodutível".

Historicamente, é durante o processo de abstração, em curso na pintura impressionista, e a consequente contingência da luz na representação pictórica, que a luz vai conferir à fotografia uma certa transcendência. Graças ao caráter que a fotografia assume como imagem acheiropoiete", para os primeiros fotógrafos, a luz é "a forma de escrita" da natureza, como escreve Nadar (1900), no seu livro intitulado Lápis da Natureza.

O clima de mistério e espanto que envolveu o surgimento da fotografia, autorizou algumas das mais estranhas práticas, como a "fotografia de espíritos" e a fotografia de pessoas no seu leito de morte. A fotografia mortuária chegou a ser uma das principais atividades do fotógrafo comercial do século XIX. E, segundo Krauss (2002, pp. 26-29) Balzac, para elaborar a sua "Teoria dos Espetros", serviu-se da luz para produzir os seus "espetros" em experimentos fotográficos. Como observa Margarida de Medeiros (2010, p. 17), "a dimensão automática da imagem fotográfica convocou muitos fantasmas, positivos e negativos, eufóricos e disfóricos desde a sua invenção".

Ocupando um lugar ambíguo na confluência entre a ciência e o espiritismo, a fotografia participa do pensamento positivista e, ao mesmo tempo, toma parte na ordem de inteligibilidade dos metafísicos. Nesse sentido, a fotografia parece concretizar, ao nível dos mecanismos da representação imagética, os ideais de imparcialidade e objetividade do paradigma positivista da modernidade, que viria sanar a crise da representação pictórica aberta pelo Impressionismo. Unindo a ciência à transcendência (o "espanto", de que fala Frade (1992), e o misticismo a que se presta a sua interpretação), a fotografia realiza o sonho de uma linguagem universal, assumindo-se como "o privilégio de um olhar moderno" (Mah, 2003).

Segundo André Bazin (1945/1981, p. 10), no modernismo, a fotografia torna-se a divisa de uma estética com um duplo sentido: enfatiza a fotografia como prática da doxa realista e projeta um novo campo de interesses para as artes plásticas, libertando-as da obsessão da semelhança e da realidade. Se a fotografia no seu aparecimento se assume

\footnotetext{
7 Uma imagem acheiropoiete é uma imagem produzida sem a intervenção de mão humana (como as imagens de Platão), uma vez que o papel do fotógrafo é minimizado, enquanto intermediário cuja mediação entre a representação e o real é neutra, analógica e automática.
} 
como um espelho, ou analogon da realidade, mais tarde, na década de 60 do século $X X$, ocorre nela uma reação crítica, a partir de diferentes territórios disciplinares, que denuncia a conceção da fotografia como cópia não mediatizada do real, evidenciando os aspetos da fotografia como transformação do real face à suposta transparência do meio. Curiosamente, esta conceção, que assinala uma desconfiança face à objetividade da imagem fotográfica e que desencadeou um retorno em força ao artefacto e à intervenção exibida do artista nos processos mediáticos, funda-se na crença de uma verdade interior, que não se confunde com as aparências do real.

Como mostra Philippe Dubois (1992, p. 110), não obstante as diversas posições tomadas pela crítica $^{8}$, o aparecimento da fotografia permitiu revelar uma relação entre a representação e o real, que existia já desde os primórdios da própria representação - a noção peirceana do índice. A pintura, enquanto dispositivo teórico, era já trabalhada pelo problema da contiguidade do referente, tanto quanto pelo problema da semelhança. Quer se trate da origem histórica (as grutas de Lascaux), da origem fabulosa (as histórias de sombras de Plínio e Platão) ${ }^{9}$, ou da origem mitológica (os espelhos de Narciso e Medusa), em todos os casos, a representação nasceu por contacto.

A conceção da fotografia baseada na noção peirceana do índice tem como ponto de partida a sua natureza técnica, o princípio de impressão luminosa. Mas distingue-se nitidamente das duas conceções precedentes, ao dotar a imagem indiciária de um valor singular, determinado unicamente pelo seu referente. A fotografia integra aqui a categoria dos signos entre os quais se incluem "o fumo (índice de um fogo), a sombra projetada (índice de uma presença), a cicatriz (marca de uma ferida), a ruína (vestígio do que lá esteve), o sintoma (de uma doença)" (Dubois, 1992, p. 44).

O princípio do vestígio assinala apenas um momento no conjunto do processo fotográfico. No entanto, é esse momento em que a fotografia é "dada à luz", que lhe confere uma genética nova, diferente da pintura. Somente durante o instante do ato, a fotografia pode ser considerada como um "puro acto-vestígio" ou, segundo a terminologia bartheseana, "uma mensagem sem código" (Barthes, 1989, p. 125). Nesse instante de esquecimento dos códigos, há uma falha na qual, pela luz, é registada uma existência, como no livro da vida. Através da singularidade extrema desta relação de conexão, a imagem-índice reenvia a um seu referente determinado, designando-o e testemunhando a sua existência - o "isto foi", com que Barthes (1989, pp 17-101) enuncia o noema da fotografia e que constitui a "ciência impossível do ser único".

A fotografia deixa-se interpretar em termos congruentes pela história da arte. Porém, tal facto não define a sua essência. A tentativa de classificação da fotografia parece querer esquivar-se sempre, uma vez que ela não constitui um corpus, "apenas alguns corpos" (Barthes, 1989, pp. 16-22). Para o bem e/ou para o mal, a imagem-índice confronta-nos com a nossa relação com outros objetos e outros sujeitos. A "teimosia do referente", que a imagem manifesta, revela o estado da nossa alma.

\footnotetext{
${ }^{8}$ As posições tomadas pela crítica quanto ao princípio da realidade na fotografia são os seguintes: o discurso da mimese, o discurso do código e o discurso da desconstrução, assim como o seu correspondente estatuto indicial.

9 Sob este ponto de vista, as sombras e os reflexos (phantasmata) de Platão parecem corresponder à moderna definição de índice.
} 
Historicamente, a noção peirceana inscreve-se num projeto global de passagem da categoria do ícone à categoria do índice. Esta passagem, entrevista como uma semiosis, e não apenas como marca da modernidade, é um verdadeiro deslocamento histórico, onde uma estética (clássica) da mimesis, da analogia e da semântica (a ordem da metáfora) cederia o lugar a uma estética do vestígio, do contacto e da contiguidade referencial (a ordem da metonímia). A ordem do índice revela-se, assim, um instrumento conceptual singular, que dá conta do funcionamento das novas formas de Arte Contemporânea.

Rosalind Krauss (2002) aprofunda a emergência e a radicalização da lógica do índice na Arte Contemporânea, não apenas identificando claramente o espaço outorgado à fotografia nos movimentos da segunda vanguarda do século XX, como a Body Art ou a Land Art, como mas reconhecendo nestas manifestações a influência do modelo fotográfico do traço, do rasto e do vestígio - exibido no corpo ou marcado no chão - enquanto índice de um gesto e sintoma de um tempo. O próprio ready-made duchampiano, concebido como instantâneo, transforma-se no traço de um acontecimento particular - um acto de enunciação - o equivalente dos significantes verbais do tipo "isto" ou "aquilo", que Barthes teoriza (1989, pp. 84-85).

A fotografia serviu, em determinado momento, para abalar o universo estético da diferenciação, introduzindo a inquietante eventualidade da substituição da diferença qualitativa por uma simples paleta de diferenças quantitativas, como acontece com as séries. Esse desmoronamento da noção de diferença, com enorme impacto nas práticas artísticas tradicionalmente "distintas", revela, em todo o gesto artístico, a multiplicidade, a ficção, a repetição e o estereótipo (Barthes, 1989, pp. 223-224).

Contrariamente ao que pensava Pierre Bourdieu (1989) ${ }^{10}$, a fotografia constituiu-se como um discurso crítico que se inscreve num vasto projeto de desconstrução em que "a arte se distancia de si mesma" (Krauss, 2002, p. 226), mas talvez nos aproxime uns dos outros: "mostrem as vossas fotos a qualquer pessoa; ela mostrará as suas" (Barthes, 1989, p. 18). Nesse sentido, a fotografia obedece menos à lógica do discurso estético (à lógica do autor) do que à lógica do álbum, do arquivo, da viagem e da reportagem. Uma foto nunca se distingue do seu referente - "um cachimbo é sempre um cachimbo". Essa fatalidade ou "teimosia do referente" arrasta a fotografia para a imensa desordem dos objetos - de todos os objetos do mundo" (Barthes, 1989, pp. 18-19).

A prática do múltiplo - quer se trate de centenas de cópias reproduzidas mecanicamente (como as serigrafias de Andy Warhol), ou de centenas de fotos indiferenciáveis (como as de qualquer turista), abala a distinção entre o original e a cópia, os autores e os outros, assim como a própria noção de autenticidade, fazendo regressar a distinção

\footnotetext{
10 Para Bourdieu, a fotografia nunca poderá ser um discurso estético propriamente dito, porque não possui regras próprias, mas toma emprestados os seus critérios das outras artes. É "uma arte que imita a arte" (Bourdieu, 1965/2003, p. 135), como se essa não fosse uma definição (atribuída a André Malraux) para todas as artes. A fotografia desempenha, do ponto de vista sociológico, a função de índice social ou prova de unidade familiar. É um objeto de trocas reguladas e atividades estereotipadas. O seu âmbito é o dos ritos de culto doméstico (Bourdieu, 1965/2003, pp. 57-58).

"Como diria Georges Kubler (1998, pp. 13-14), todos os objetos marcam a passagem do tempo A fotografia parece concretizar a visão de Kubler de um alargamento do conceito de arte, de modo a abarcar toda a espécie de objetos fabricados pelo Homem, fazendo coincidir o universo dos objetos em geral com a História da Arte.
} 
entre o original e a cópia à indiferenciação, como nos primórdios dos tempos. O fotógrafo profissional e o fotógrafo de família estão aqui ligados por uma mesma prática.

Quando Moisés pede a Deus para ver "a sua glória", Deus tapa-Ihe o rosto, em sinal de proteção, e mostra-lhe o rasto da sua passagem (Êxodo 33, pp. 12-23). Com este pedido que Moisés dirige a Deus, enuncia-se toda uma tradição em que nos inscrevemos, que é caracterizada pela nossa insuficiência e insegurança, e pela nossa necessidade de ver e sermos vistos pelo rosto de quem amamos, de receber um qualquer sinal da sua presença, nem que seja o rasto/resto da sua passagem. Esta é a lógica do índice, conceito que atravessa toda a obra de Benjamin, e que chega até nós através da reflexão fotográfica.

\section{CONCLUSÕES}

Definimos "arte como atividade mágica"12, "arte como mimesis" e "arte como linguagem", como lógicas de vinculação pelas quais o homem se liga, pela arte (no sentido antropológico e lato do termo) à vida e à morte, a Deus e ao outro, à memória e ao sonho. Identificamos estas três principais lógicas de relação do homem com a arte, as quais, podendo ser historicamente diferenciadas, são tão antigas quanto contemporâneas, e na maior parte dos casos, são permutáveis e sobrepõem-se. Magia-mimesis-linguagem sucedem-se no tempo, desenhando o percurso histórico das exigências não estéticas impostas à arte dos seus primórdios até à sua autonomia e, simultaneamente, as suas motivações e conquistas.

[Magia] Tanto a produção de artefactos mágicos como a tradição da imagem, enquanto imagem do homem (patente na mimesis), estão ligadas ao caráter substitutivo da imagem-objeto, em que a função mnemónica é fundamental, uma vez que o seu objetivo é representar, ou seja, literalmente, "tornar presente um ser ausente". Tudo indica que a função primordial da estátua-retrato (tanto egípcia como grega) era a de salvar o ser pela aparência, e deter assim, o caráter evanescente do tempo. Embora com contornos diferentes, a prática do retrato prolonga esta tradição continuando hoje no centro da produção de imagens.

[Mimesis] Para Michel Melot (2015), o laço que funda a imagem não é da ordem das coisas, mas da ordem da relação: "é sempre imagem de alguma coisa ou de alguém, de quem nem por isso é cópia" (p. 12). A diferenciação entre o original e a cópia, um eventual "efeito em cadeia" (Hanfmann) no início do processo de produção de imagens, torna-se protagonista na mimesis, com a qual nos familiarizamos através da reprodução manual, mecânica, e mais tarde, digital. Aristóteles salientou o prazer da imitação como necessário ao processo de aprendizagem. Estudos da neurociência vão mais longe, sugerindo que a necessidade de mimesis parece justificar-se pelo prazer das relações positivas (que estabelecemos com as pessoas, as imagens, os espaços e/ou as coisas). 0 prazer e o desprazer são marcadores somáticos fundamentais para o nosso equilíbrio homeostático. A importância das imagens a que estamos expostos, e que copiamos

${ }^{12}$ A "arte como atividade mágica" e a "arte sob a lógica do índice" estão associadas ao caráter indicial da imagem-objeto, igualmente comum às conceções de "arte como vida" da Performance e da Body Art. 
conscientemente ou por "imitação reflexa" (em virtude do contágio neural entre nós e elas), é de tal forma vital para a nossa saúde mental e emocional, que muitas vezes, em virtude da híper-visualidade e híper-informação a que estamos expostos, somos levados a optar pela desconexão. A mimesis tecnológica corresponde, sem dúvida, a uma inversão (Martins, 2001, p. 132) 13.

[Linguagem] A partir do pensamento de Michel Foucault, as imagens passam a ser tratadas no quadro da crise da representação e da dissociação entre as palavras e as coisas - a crise da "verdadeira imagem", segundo a expressão de Hans Belting (2011) - que é, antes de mais, a crise da crença na relação entre a verdade e a imagem, e a consequente desilusão. Desta crise, que começou por ser uma crise de natureza religiosa e acabou por incidir em vários domínios, entre os quais na própria imagem, emergiu a modernidade, e o movimento da "arte pela arte" (ou arte como linguagem).

Nos dias de hoje, da imagem científica à imagem-prova, das artes visuais ao marketing, nenhuma esfera parece escapar à "imagiologia", nem tão pouco o universo da vida privada, ou o que dele resta. Porém, como salienta Sicard (2006, p. 299), a gravura, produto da arte do artesão, não instaura os mesmos olhares que a imagem da técnica fotográfica, assim como o dispositivo fotográfico não fabrica o mesmo mundo que os programas digitais, cuja propriedade escapa aos indivíduos. A história dos olhares inscreve-se tanto na história das imagens e da sua transmissão e produção como na história dos aparelhos de visão. A história das imagens e dos olhares inscreve-se sempre na história dos meios.

Uma imagem evoca sempre outras imagens, uma vez que, como explica Belting (2014, p. 11), as imagens são respostas historicamente contingentes e, nesse sentido, desajustadas no que respeita às necessidades das gerações sucessivas. Por isso mesmo, são necessárias sempre mais e novas imagens (nem que sejam "novas" apenas aparentemente) para responder a questões intemporais do ser, comuns à arte e à religião.

A importância da arte e da sua ascendência mítico-religiosa na redefinição da imagem mediática reside na interdependência entre a imagem e o meio. Em termos antropológicos, a arte está entre os primeiros meios de extensão do olhar. Da sombra das origens ao paradigma especular, e deste aos "espelhos eletrónicos" (Belting, 2014, p. 45), a arte atualiza as imagens da nossa relação com o mundo através dos meios postos à nossa disposição em cada época. Com efeito, a arte, quaisquer que sejam os meios disponíveis, constitui o lugar onde se forjam os significados perdidos nos processos de transmissão, associação e reminiscência das imagens, afinal, o lugar da produção simbólica.

\section{REFERÊNCIAS BIBLIOGRÁFICAS}

Argan, G. C. (1984). Arte e critica d'arte. Roma-Bari: Laterza.

Barthes, R. (1989). A câmara clara. Lisboa: Edições 70.

Barr, D. (2003). Imagens (pictures) para una representación contemporânea. Madrid: Mimesis.

\footnotetext{
${ }^{13}$ Sobre a mimesis tecnológica, ver Comunicação e Sociedade, 22 (2012), um número organizado por Nelson Zagalo e Pedro Branco, consagrado às "Tecnologias Criativas".
} 
Bazin, A. (1945/1981). Ontologie de l'image photographique. In A. Bazin, Qu'est-ce que le Cinéma? (pp. 9-17). Paris: Édition du Cerf.

Belting, H. (2011). A verdadeira imagem. Entre fé e a suspeita das imagens: cenários históricos. Lisboa: Dafne Editora.

Belting, H. (2014). Antropologia da imagem: para uma ciência da imagem. Lisboa: Editora KKYM + EAUM.

Benjamin, W. (1936-1939/1992). A obra de arte na era da sua reprodutibilidade técnica. In W. Benjamin, Sobre Arte, Técnica, Linguagem e Política (pp. 71-113). Lisboa: Relógio d’Água.

Benjamin, W. (1982/2009). Passagens. Belo Horizonte: Editora UFMG; São Paulo: Editora Oficial Estado de São Paulo.

Bourdieu, P. (Ed.) (1965/2003). Un arte medio. Ensayo sobre los usos sociales de la fotografia. Barcelona: Editorial Gustavo Gili.

Clair, J. (1992). Critica della modernitá. Milano: Umberto Allemandi \& C.

Damásio, A. R. (2003). Ao encontro de Espinosa: as emoções sociais e a neurologia do sentir. Mem-Martins: Publicações Europa-América.

Debray, R. (1994). Vida e morte da imagem. Uma história do olhar no Ocidente. Petrópolis: Vozes.

Dubois, P. (1992). O acto fotográfico. Lisboa: Vega.

Foucault, M. (1966/1998). As palavras e as coisas. Uma arqueologia das ciências humanas. Lisboa: Edições 70.

Goleman, D. (2006). Inteligência social. A nova ciência do relacionamento humano. Lisboa: Temas e Debates Actividades Editoriais, Lda.

Gombrich, E. H. (1985). A história da arte. Rio de Janeiro: Zahar Editores.

Gombrich, E. H. (1959/1986). Arte e Ilusão. Um Estudo da Psicologia da Representação Pictórica. S. Paulo: Martins Fontes.

Hauser, A. (1951). História social da arte e da cultura, Vol. 1: Os tempos pré-históricos. Grécia e Roma. Lisboa: Vega.

Krauss, R. (2002). O fotográfico. Barcelona: Editorial Gustavo Gili.

Levin, Kim (1971). The eye of Ra. In Ashbery, J. \& Hiess, T. B. (Eds.), Light in Art (pp. 23-36). Nova lorque: Collier Books.

Melot, M. (2015). Uma breve história da imagem. Vila Nova de Famalicão: Húmus \& CECS.

Malraux, A. (1965/2000). O museu imaginário. Lisboa: Edições 70.

Martins, M. L. (2011). O que podem as imagens. Trajeto do uno ao múltiplo. In Martins, M. L.; Oliveira, M.; Miranda, B. \& Godinho, J. (Eds.), Imagem e Pensamento (pp. 129-135). Coimbra: Grácio Editor.

Medeiros, M. (2010). Fotografia e verdade. Uma história de fantasmas. Lisboa: Assírio \& Alvim.

Menna, F. (1983). La linea analitica dell'arte moderna. Torino: Piccola Biblioteca Einaudi.

Nancy, J.-L. (2006). La mirada del retrato. Buenos Aires - Madrid: Amorrortu. 
Platão (Séc. IV a.C./2010). A República. Lisboa: Fundação Calouste Gulbenkian.

Platão (Séc. IV a.C./2012). O sofista. Lisboa: Fundação Calouste Gulbenkian.

Plinio, o Velho [Caio Plinio Secondo] (c. 1470-1561). Historia naturale (Libro XXXV, pp. 1084-1120). VeneziaFerrara: Giacomo Vidale.

Pinto, S. (2015). Para uma semiótica da luz. Da visão mítica aos regimes escópicos da Contemporaneidade. Tese de Doutoramento, Universidade do Minho, Braga, Portugal.

Sicard, M. (2006). A fábrica do olhar. Imagens de ciência e aparelhos de visão [Século XV-XX]. Lisboa: Edições 70.

Sontag, S. (1986). Ensaios sobre fotografia. Lisboa: Publicações Dom Quixote.

Steiner, G. (1993). Presenças reais. As artes do sentido. Lisboa: Editorial Presença.

Stoichita, V. (2008). Breve storia dell'ombra. Milano: II Saggiatore.

Zagalo, N. \& Branco, P. (Eds.) (2012). Comunicação e Sociedade, 22.

\section{NOTAS BIOGRÁFICAS}

Sílvia Pinto é Artista Plástica \& Multimédia e Professora Auxiliar na Universidade Lusófona, de Cultura e Arte em Rede e de Cibercultura. Também leccionou na Escola Superior Artística do Porto (2001-2016), nos Cursos de Artes Visuais - Fotografia, Design e Comunicação Multimédia, Artes Plásticas e no Mestrado em Ilustração. Participou em exposições individuais e coletivas no Porto, Bolonha, Berlim, Barcelona e Roterdão (Oporto-Rotterdam Capitals of Cultural 2001), e recebeu apoio financeiro da Fundação Calouste Gulbenkian para a exposição Encruzilhada (2006). Para mais informações ver: www.silviapinto.com.pt

Licenciada Summa cum Laude em Artes Plásticas - Pintura, pela Accademia di Belle Arti di Bologna (2001) e Doutorada em Ciências da Comunicação - Especialidade em Semiótica Social, pela Universidade do Minho (2015), investiga, fundamentalmente, nos âmbitos da Arte, Comunicação \& Semiótica e Estudos Culturais. Publicou, entre outros artigos, "A luz e a sombra como extensões do homem" (com Moisés Martins \& Madalena Oliveira, 2017); "Da luz e do sentido" (com Madalena Oliveira, 2016); "Regimes Escópicos" (2014) e "Cavernas da contemporaneidade" (2014).

E-mail: silvia.pinto.07@gmail.com

Rua Alcino Araújo, 59 D - $3^{\circ}$ D, 4410-218 S. Félix da Marinha, Portugal

Moisés de Lemos Martins é Professor Catedrático da Universidade do Minho. Doutorou-se em Ciências Sociais na Universidade de Ciências Humanas de Estrasburgo (1984). Ensina e investiga em semiótica social, sociologia da comunicação e da cultura, comunicação intercultural, estudos lusófonos. Dirige o Centro de Estudos de Comunicação e Sociedade (CECS), que fundou em 2001. É Diretor da revista Comunicação e Sociedade, e também da Revista Lusófona de Estudos Culturais. Presidiu à Sopcom, Lusocom 
e Confibercom. Publicou ou editou, entre outros livros: Lusofonia e Interculturalidade (2015); Do post ao postal (com Maria da Luz Correia); Crise no Castelo da Cultura (2011); L'imaginaire des médias (com Michel Maffesoli, 2011), Portugal Ilustrado em Postais (com Madalena Oliveira, 2011); Caminhos nas Ciências Sociais (2010); Comunicação e Lusofonia (com Helena Sousa e Rosa Cabecinhas, 2006); A Linguagem, a Verdade e o Poder (2002); Para uma Inversa Navegação (1996); O Olho de Deus no Discurso Salazarista (1990).

E-mail: moisesm@ics.uminho.pt

Instituto de Ciências Sociais, Universidade do Minho, Campus de Gualtar, 4710057, Braga, Portugal

* Submetido: 17-10-2016

* Aceite: 22-01-2017 